\title{
Technologies for an Aging Society: A Systematic Review of "Smart Home" Applications
}

\author{
G. Demiris', B. K. Hensel ${ }^{2}$ \\ 'Biomedical and Health Informatics, University of Washington, Seattle, WA, USA \\ ${ }^{2}$ Health Management and Informatics, University of Missouri-Columbia, Columbia, MO, USA
}

\section{Introduction}

The increase in life expectancy and ongoing growth of the older adult population have led to new models of aging that empower people to lead fulfilling lives in the residence of their choice. Independence is a critical issue not only for older adults but also people with chronic conditions or disabilities who wish to remain at home and increase their quality of life. As individuals try to cope with health related issues such as falls, sensory impairment, diminished mobility, isolation, and medication management, they seek solutions that will enhance their lives and allow them to stay at home. As technology advances, many of these solutions can utilize informatics applications that promote well-being and enable monitoring of one's health status. "Smart home" developments are being pursued worldwide in response to advancing technology, rising health care costs and the desire of older adults and individuals with chronic conditions to remain independent at the residence of their choice.

The term "smart home" refers to a residence equipped with technology that facilitates monitoring of residents and/ or promotes independence and increases residents' quality of life. The technology is integrated into the infrastructure of the residence and does not in principle require training of or operation by the resident, distinguishing thereby smart home applications from stand alone units that can be used in the home setting and need to be operated by the end-user (e.g., blood pressure cuffs, videophones, etc.). The developments in this domain have led to the introduction of new terms such as gerontechnology, domotics and ubiquitous computing to describe trends and sub-areas of research. The term "gerontechnology" was coined to describe an interdisciplinary field of scientific research of technological applications (including smart homes) that are directed "towards the aspirations and opportunities for the elderly person." [1] The term "domotics" (combining the words domus, Latin for "home," and informatics) describes the study of information technology applications that become part of the residential structure.

\section{Objectives}

The aim of this paper is to provide a comprehensive review of smart home projects worldwide and discuss technologies and models used in this context as well as findings of the evaluation of such projects. The focus is on smart homes that aim to monitor and improve health related parameters, what Rialle et al. [2] call "health smart homes." Thus, studies and projects described in the environmental design literature, where the term "smart home" refers to facilities designed to improve energy efficiency and ventilation, were not part of the focus of this paper. Furthermore, we aim to discuss human 
factor challenges and emerging trends in the development and evaluation of smart homes.

\section{Methods}

We conducted a systematic literature review of smart home projects and studies. The term "smart home" is relatively new in scientific literature. Thus, we used the search terms "smart home," "home based technology," "home monitoring," "sensors," "domotics," and "gerontechnology," along with various synonyms for each of these concepts. To cover not only the medical but also the social sciences and electronics literature, we conducted extensive searches across disciplines in the following bibliographical databases: Medline (Ovid, 1966-October 2007), Embase (Ovid, 1980-week 50, 2007), CINAHL (Ovid, 1982-October 2007), PsycINFO (Ovid, 1972-October 2007), Evidence Based Medicine Reviews (Ovid, second quarter 2007), Electronics and Communications Abstracts (CSA, 1981-October 2007), Computer and Information Systems Abstracts (CSA, 1981-October 2007), Educational Resources Information Center (ERIC; CSA, 1966-October 2007), Library and Information Science Abstracts (LISA, 1969-October 2007), ProQuest Digital Dissertations (ProQuest, 1997- October 2007), Web of Science (ISI, 1980-October 2007).To maximize recall we applied no methodological filters. In order to be inclusive of all new initiatives and efforts in this area given the innovativeness of the concept, we manually searched for relevant references in the retrieved articles as well as three published books on smart homes and gerontechnology[3-5]. Finally, we searched Google Scholar using the same search terms (October 2007).
Inclusion criteria included technologies that were integrated into the residential infrastructure, providing a true smart home solution, and projects that were beyond the initial conceptualization phase and were in the actual phase of implementation, maintenance, or evaluation. Exclusion criteria included technologies that were not part of the residential infrastructure but rather stand-alone devices in the home such as blood pressure monitors or glucose meters, and publications that were theoretical or concept papers discussing the importance of smart homes without focusing on a specific initiative. Furthermore, we excluded projects that did not have a health related component and, as described earlier, were instead focusing on home based technology for other areas such as energy efficiency. Studies and other publications were reviewed by the two authors and projects were identified. Project aim, technology used and target audience were extracted and documented for each project. Most projects included more than one publication.

An additional search for findings of health outcomes for the identified smart home projects was conducted (November 2007). The name or title of each project was entered in both Medline and Google Scholar and results were reviewed for associated research on health outcomes.

\section{Results}

The identified smart home projects utilize a wide range of technologies serving different goals. Table 1 summarizes the different categories of smart home technologies. For example, physiological monitoring assesses physiological

Table 1 Definitions of the types of health-related smart home technologies

\begin{tabular}{l} 
Categories of health-related smart home technologies and their definitions \\
\hline Physiological monitoring (Phys) \\
Collection and analysis of data pertaining to physiological measurements such as vital signs of pulse, respiration, temperature, and \\
blood pressure, as well as blood sugar level, bladder and bowel output, etc. \\
Functional monitoring/ Emergency detection and response (Fx) \\
Collection and analysis of data pertaining to functional measurements such as general activity level, motion, gait, meal intake, and \\
other activities-of-daily-living. Emergency detection is enabled through the collection of data that indicate abnormal or critical \\
situations (such as falls). \\
Safety monitoring and assistance (Saf) \\
Collection and analysis of data pertaining to measurements that detect environmental hazards such as fire or gas leak. Safety \\
assistance includes functions such as automatic turning on off bathroom lights when getting out of bed, facilitating safety by \\
reducing trips and falls. Location technologies aimed at safety also fit into this type. \\
Security monitoring and assistance (Sec) \\
Measurements that detect human threats such as intruders. Assistance includes responses to identified threats. \\
Social interaction monitoring and assistance (Soc) \\
Collection and analysis of data pertaining to social interactions such as phone calls, visitors, and participation in activities. Social \\
interaction assistance includes technologies that facilitate social interaction, such as video-based components that support video- \\
mediated communication with friends and loved ones, virtual participation in group activities etc. \\
Cognitive and sensory assistance (Cog/Sen) \\
Cognitive assistance technologies include those of automated or self-initiated reminders and other cognitive aids such as medication \\
reminder and management tools, lost key locators, etc, for users with identified memory deficits. They also include task instruction \\
technologies, such as verbal instructions in using an appliance. Sensory assistance includes technologies that aid users with sensory \\
deficits such as for sight, hearing, and touch (e.g., water temperature).
\end{tabular}


measures such as vital signs, bowel and bladder output, etc. Functional monitors measure ability in activities of daily living, such as walking (gait). Safety monitors detect environmental hazards such as fires or gas leaks and consequently trigger alerts. Security monitors detect and alert to human threats such as intruders. Social interaction technologies measure and facilitate social contact and include information and communication applications. Finally, cognitive and sensory technologies include cognitive aids such as reminders and provide assistance with deficits in sight, hearing, and touch.

A total of 114 publications (including papers, abstracts and web pages) were identified and reviewed to identify the overarching projects. Table 2 lists all twenty one smart home projects identified by the systematic search. This table is by no means an exhaustive list of all smart home initiatives worldwide but rather a comprehensive collection of projects that have published their design, implementation or findings in scientific literature and fulfilled the inclusion criteria of our study.

The list includes geographically and technologically diverse projects from Europe, the US and Asia. The Center for Future Health at the University of Rochester, New York in the US, for example, has developed a Smart Medical Home as a highly controlled environment including infrared sensors, biosensors, and video cameras [6]. The Aware Home at the Georgia Institute of Technology explores ubiquitous computing technologies that sense and identify potential crises, assist a senior adult's memory and track behavioral trends [7]. Researchers from five countries (the UK, Ireland, Finland, Lithuania and Norway) joined their efforts for the ENABLE project [8], which promotes the wellbeing of people with early dementia with several fea- tures such as a locator for lost objects, a temperature monitor and an automatic bedroom light. In Toulouse, France, the PROSAFE project is utilizing a set of infrared motion sensors to support automatic recognition of resident activity and possible falls [9].

Table 3 provides a summary of the number and percentages of smart home project sites with specific types of technologies. Most of the identified projects $(71 \%)$ include technologies for functional monitoring, $67 \%$ for safety monitoring, $47 \%$ for physiological monitoring, $43 \%$ for cognitive support or sensory aids, $19 \%$ for monitoring security and $19 \%$ to increase social interaction

\section{Discussion}

The concept of smart homes refers to an innovative concept that integrates technology within residences in order to maintain and even enhance functional health, security, safety and quality of life of their residents. A smart home aims to enable non-obtrusive monitoring of residents and involves different levels of technological sophistication, ranging from stand-alone intelligent devices to homes that continuously monitor residents' activities and physical status and adapt to residents' needs, often providing proactive measures. The concept of smart homes is relatively new and requires research to address important questions, including those of health outcomes, clinical algorithms to indicate potential health problems, user perceptions and acceptance, and ethical implications.

When examining the types of technologies used (listed on Table 3), it becomes clear that the current state of smart homes shows relatively less focus on technologies that monitor and/or facilitate social interaction. This may possi- bly be due to a prioritization of physical and functional health in development of the new concept of smart homes. Additionally, social interaction technologies may be more difficult to integrate into the home. Interestingly, the number of sites with functional monitoring was larger than the number with more traditional physiological monitoring. Vital signs are more granular in their detection than motions in a room or restlessness in bed. Monitoring pulse or respiration passively through integrated technology is more difficult than measuring them actively through stand-alone devices. The final observation concerns cognitive/sensory aids. These types of technologies were the fourth most prevalent found. Moreover, some of the smart home projects are specifically focused on serving residents with Alzheimer's disease and dementia.

None of the studies present evidence of the effects of smart homes on health outcomes, including earlier disease, illness, and injury detection and intervention. No research was found addressing the effect of a smart home on acute episodes requiring emergency care or a possible delay or prevention of nursing home placement. Ultimately, such questions will necessitate large randomized and controlled studies, possible only with more widespread penetration of smart homes.

Proliferation of smart homes depends on user acceptance of the concept. There are a number of reasons why users may be hesitant to adopt smart homes. Such research must be placed in a conceptual framework in order to generalize consumer perceptions and systematically inform the design and implementation of smart homes. In this context, the concept of obtrusiveness, defined as "a summary evaluation by the user based on characteristics or effects associated with the technology that are 


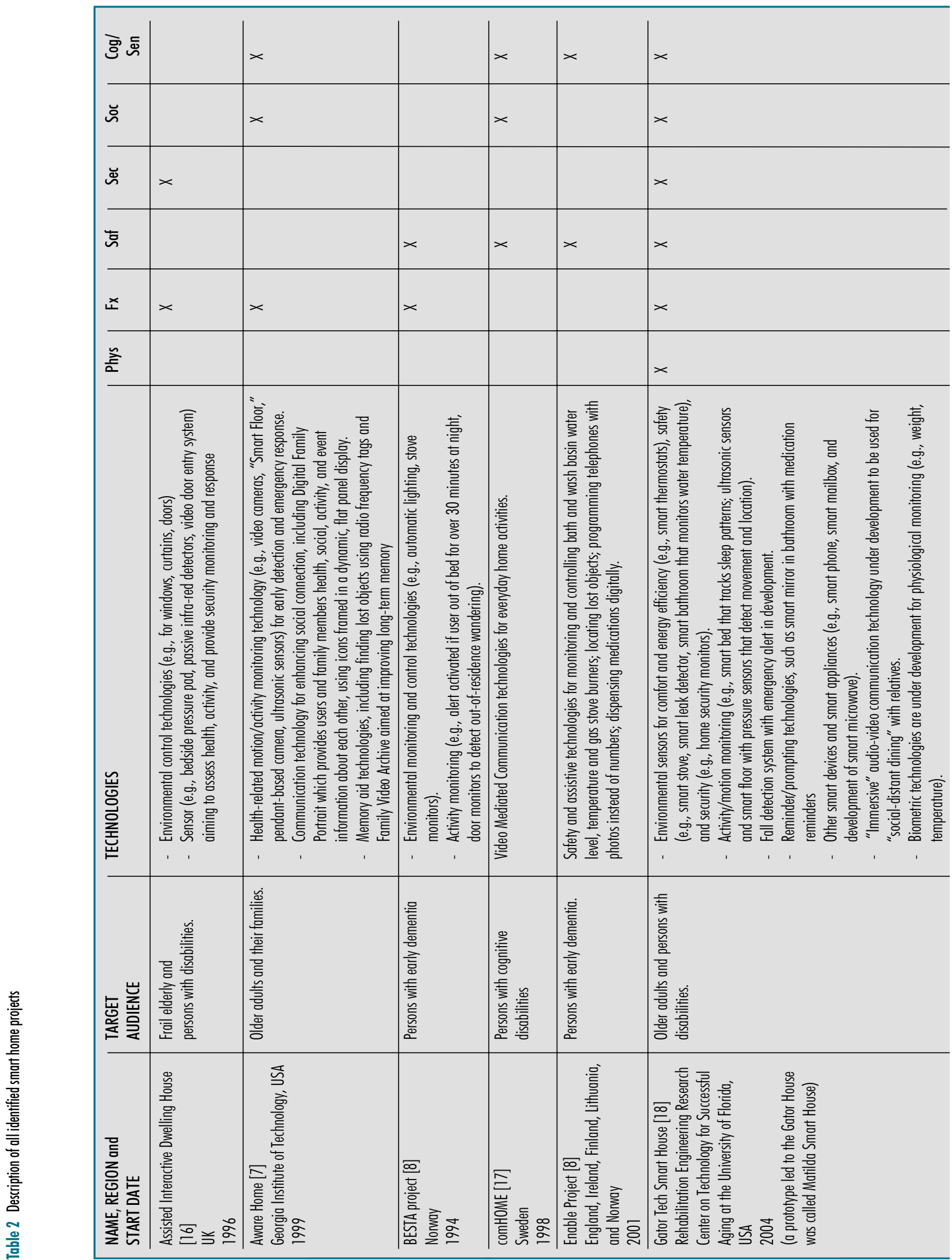




\begin{tabular}{|c|c|c|c|c|c|c|c|c|}
\hline$x$ & & & & & & $\times$ & & \\
\hline & & & $\times$ & & & & & \\
\hline \multirow[t]{3}{*}{$\times$} & $\times$ & & $\times$ & & & $\times$ & $\times$ & $\times$ \\
\hline & $\times$ & $x$ & $\times$ & $\times$ & $\times$ & $\times$ & $\times$ & $\times$ \\
\hline & $\times$ & $\times$ & $\times$ & $\times$ & & & $\times$ & $\times$ \\
\hline 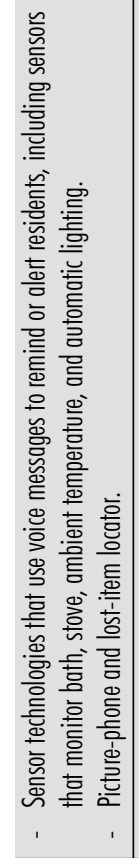 & 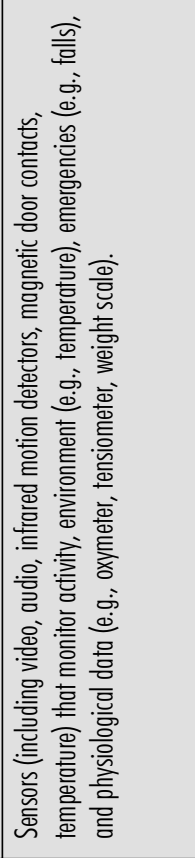 & 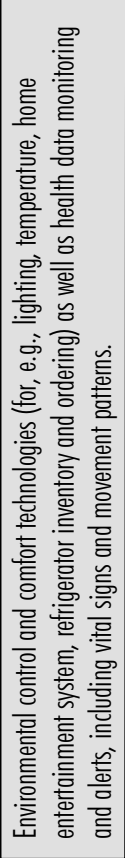 & 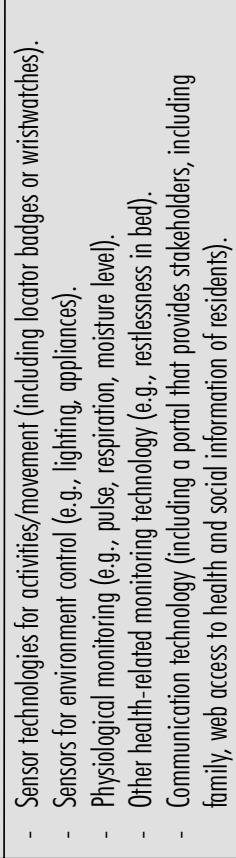 & 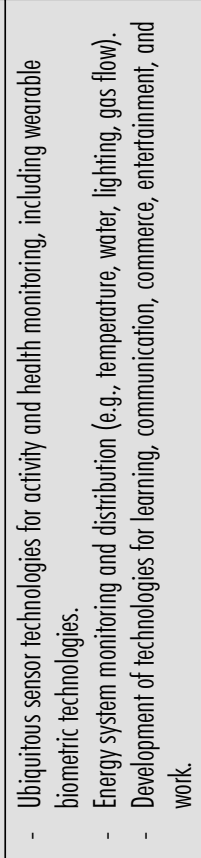 & 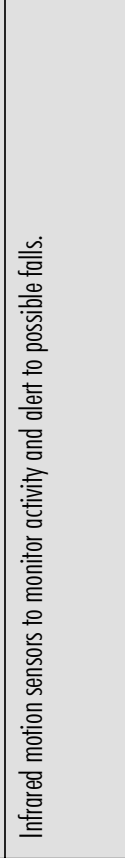 & 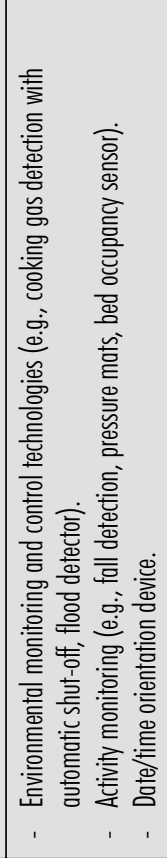 & 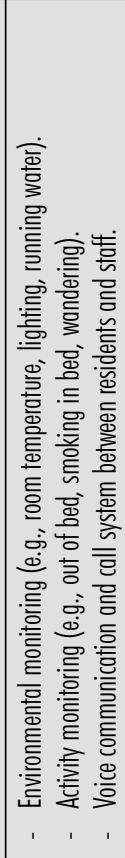 & 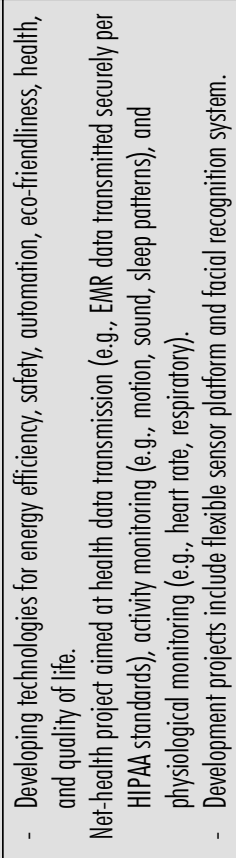 \\
\hline 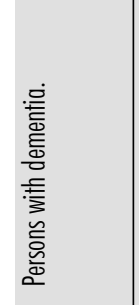 & 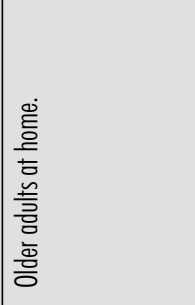 & 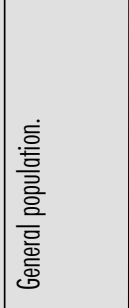 & 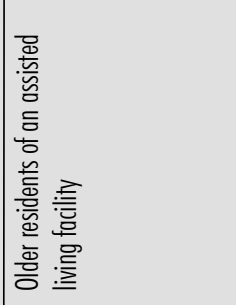 & 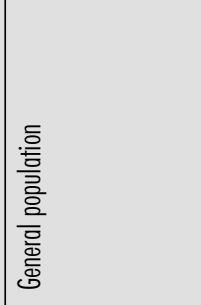 & 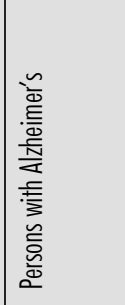 & 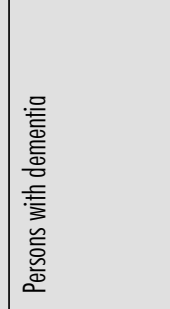 & 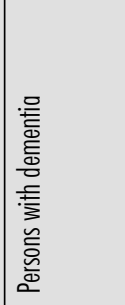 & 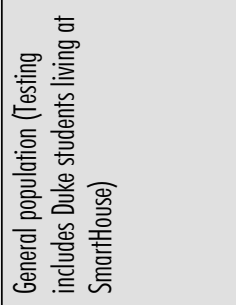 \\
\hline 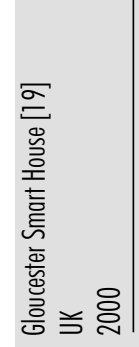 & 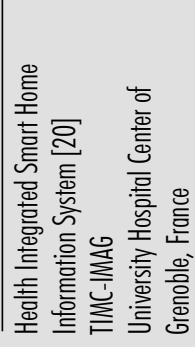 & 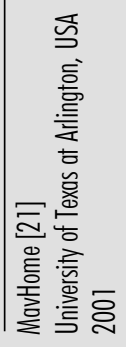 & 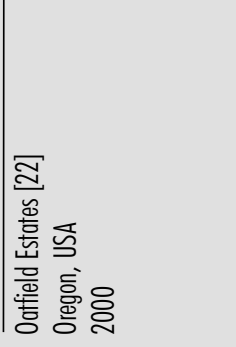 & 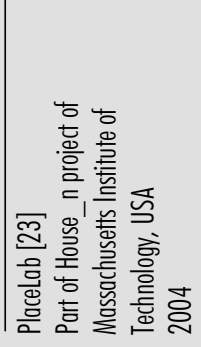 & 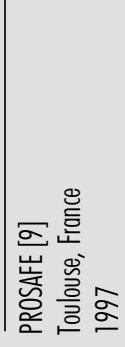 & 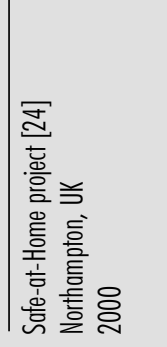 & 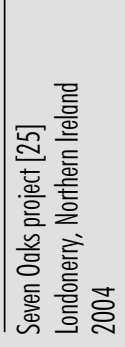 & 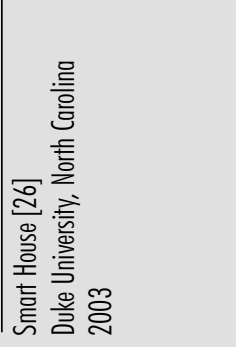 \\
\hline
\end{tabular}




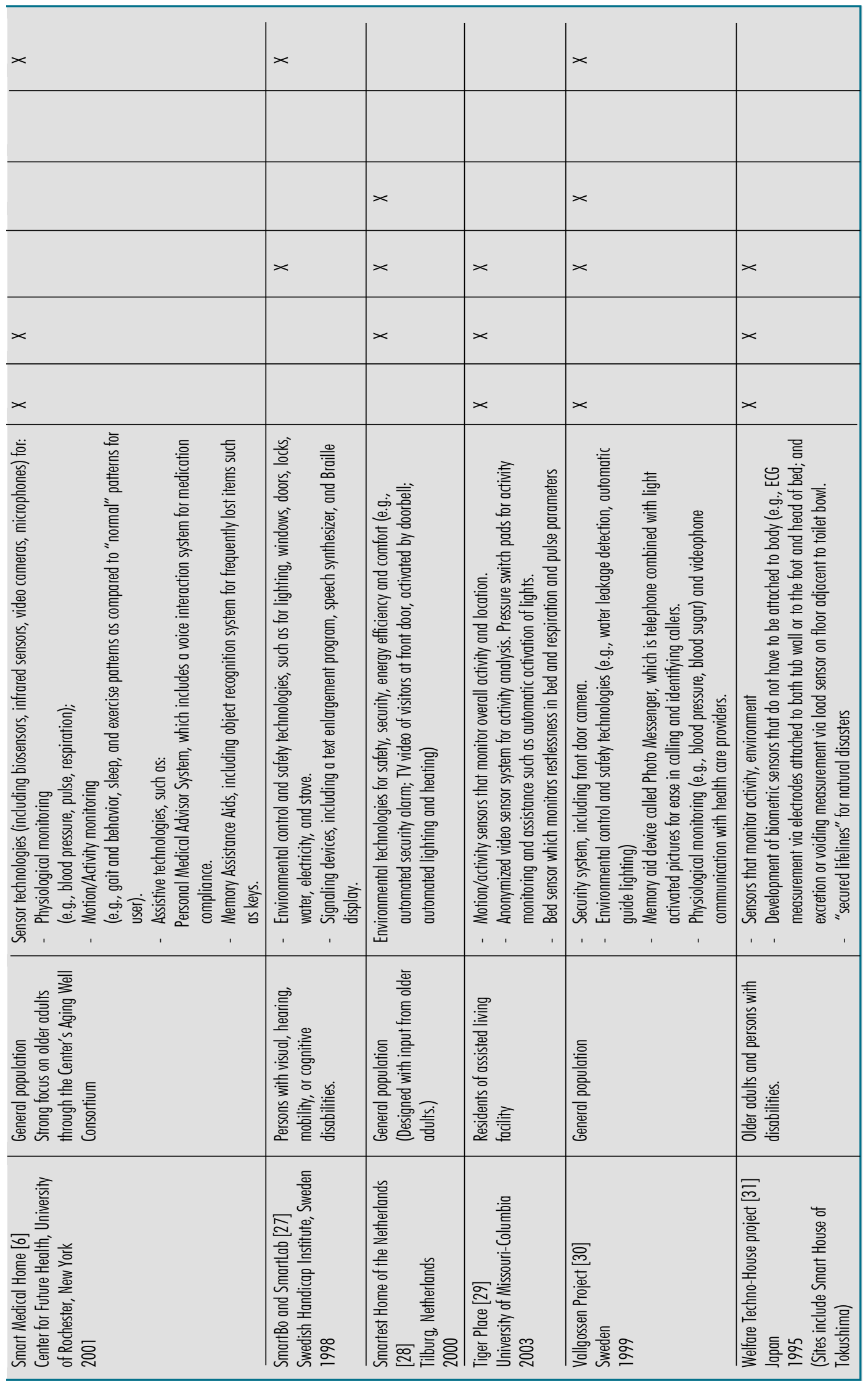


Table 3 Overview of smart home projects and types of monitoring technologies

\begin{tabular}{|c|c|c|}
\hline Types & $\begin{array}{l}\text { Number }(\%) \text { of projects } \\
(n=21)\end{array}$ & Examples \\
\hline Physiological monitoring (Phys) & $10(47 \%)$ & $\begin{array}{l}\text { Blood pressure, pulse, respiration, } \\
\text { temperature, weight, ECG, bowel and bladder } \\
\text { voiding monitoring }\end{array}$ \\
\hline $\begin{array}{l}\text { Functional monitoring/ Emergency detection and } \\
\text { response }\left(F_{x}\right)\end{array}$ & $15(71 \%)$ & $\begin{array}{l}\text { Motion/ Activity monitors, Floor sensors, Gait } \\
\text { monitors, Bed sensors }\end{array}$ \\
\hline Safety monitoring and assistance (Saf) & $14(67 \%)$ & $\begin{array}{l}\text { Water temp., stove sensors, Automatic light } \\
\text { activation }\end{array}$ \\
\hline Security monitoring and assistance (Sec) & $4(19 \%)$ & Security alarm systems \\
\hline Social interaction monitoring and assistance (Soc) & $4(19 \%)$ & $\begin{array}{l}\text { Portals with user / family health /well-being } \\
\text { information, Smart phones }\end{array}$ \\
\hline Cognitive and sensory assistance (Cog/Sen) & $9(43 \%)$ & $\begin{array}{l}\text { Object locators, Recognition aids, using } \\
\text { pictures /video, Medication reminder systems, } \\
\text { Signaling devices for sensory deficits }\end{array}$ \\
\hline
\end{tabular}

perceived as undesirable and physically and/or psychologically prominent" [10], needs to be examined.

A related question concerns the actual target audience that ultimately will comprise the "market" for health smart homes. Research has shown that people weigh their perceived need for such health care technology against their perceived obtrusiveness of it [11]. Lastly, the research agenda for smart homes must include development of an ethical framework for their design and implementation. Implications, including those for social relationships and interaction, over-reliance, and privacy, must be fully considered. Moran [12] was one of the first to pose crucial questions about the social impact of smart technologies. She stated that

"The introduction of advanced technology into the home has the potential to change qualitative and quantitative aspects of relationships between household members, as well as the role and function of the home and its relationship with the wider environment. Such technologies consequently have important implications for our health and quality of life."
In the context of smart homes, one needs to address the possibility of such technologies removing choice and control from users as they learn to rely on automation. There are fears that smart homes may result in a reduction of social interaction, or may provide tools that substitute for personal forms of care and communication [13]. Thus, it is important to consider when discussing the design of smart home applications the warning by Wyde and Valins, [14] that we may be creating "societies of high tech hermits."

A further concern, as is the case with informatics applications that capture personal health information and involve multiple stakeholders, is that of transfer of personal information to third parties potentially without proper consent.

Additionally, the degree to which smart homes lessen the sense of personal responsibility on the part of users or their caregivers must be weighed against associated benefits. Family caregivers may become less vigilant in monitoring health changes in their loved one and the users/residents themselves may become less vigilant in health self-monitoring and/or selfmanagement. Furthermore, further research needs to address eligibility criteria and user characteristics or clinical conditions that may be more suitable for smart home interventions than others. As Stip and Rialle point out [15], the issues of individual freedom, personal autonomy, informed consent, and confidentiality have to be examined in the context of the target population. They point out applications for residents with schizophrenia, a condition that causes distortion of reality in the form of delusions of persecution and psychosensorial phenomena, and highlight the likelihood that surveillance technologies may exacerbate such symptoms.

When examining the growth of the field, it becomes obvious that earlier applications focused on extensive monitoring of residents where the results of data mining became available to health care providers only. Recent trends, however, pursue a perhaps more patient/ resident empowering approach as systems allow end users to be in charge of the frequency and terms of monitoring, and to determine access rights for the resulting datasets. The inclusion of family members in these processes introduces new roles and dimensions for distant caregiving. Similarly, while earlier applications focused on monitoring within specific rooms or a single residence, current trends explore a ubiquitous computing philosophy that highlights the significance of assistive technology regardless of 10cation. Advances in wearable computing and wireless applications obviously support such a trend.

This review identifies existing smart home projects, their targeted audiences, and the technologies used. Thus, it provides a snapshot of the current state of a new and important health care concept. 


\section{Conclusions}

The growing field of "smart homes" highlights the emerging role for biomedical and health informatics in supporting aging and promoting quality of life for older adults. As technological advances enable sophisticated homebased solutions, we need to ensure that the design and implementation of informatics applications for older adults are not determined simply by technological advances but by the actual needs of end users. Several initiatives worldwide aim to address support of older adults at home, and employ multidisciplinary teams and a diverse set of technologies. They aim to enable aging in place, namely allowing older adults to remain at the residence of their choice for as long as possible rather than being transferred to different settings of care every tine their care needs change. In spite of the growing number of initiatives in this area, the field is in relatively early stages and is currently lacking an extensive body of evidence. Most of the identified studies demonstrate the feasibility of the technological solution or preliminary evaluation approaches with a limited number of subjects either in a laboratory setting or limited community based settings. Technical, ethical, legal, clinical, economical and organizational implications and challenges need to be studied in-depth for the field to grow further.

\section{References}

1. Bouma H. Gerontechnology: emerging technologies and their impact on aging in society. Stud Health Technol Inform 1998;48:93-104.

2. Rialle V, Duchene F, Noury N, Bajolle L, Demongeot J. Health "Smart" home: information technology for patients at home. Telemed J E Health 2002;8(4):395-409.

3. Fisk MJ. Social Alarms to Telecare: older people's services in transition. The Policy Press; 2003.
4. Harper R. Inside the Smart Home. Springer Verlag; 2003.

5. Charness N, Scaie KW, editors. Impact of Technology on Successful Aging. Springer Publishing Company; 2003.

6. Marsh J. House Calls. Rochester Review 2002;64 (3):22-6.

7. Kidd CD, Orr R, Abowd GD, Atkeson CG, Essa I A, MacIntyre B, et al. The Aware Home: A Living Laboratory for Ubiquitous Computing Research. Proceedings of CoBuild'99. Position paper, October 1999.

8. Cash M. Assistive technology and people with dementia. Reviews in Clinical Gerontology 2003;13 (4):313-9.

9. Chan M, Bocquet H, Campo E, Val T, Pous J. Alarm communication network to help carers of the elderly for safety purposes: a survey of a project. Int J Rehabil Res 1999;22:131-6.

10. Hensel BK, Demiris G, Courtney KL. Defining Obtrusiveness in Home Telehealth Technologies: A Conceptual Framework. J Am Med Inform Assoc 2006;13(4):428-31.

11. Courtney KL, Demiris G, Hensel B. Needing Smart Home Technologies: The Perspectives of Older Adults in Residential Care. Int J Med Inform (Under Review).

12. Moran R. The electronic home: Social and spatial aspects. Dublin: European Foundation for the Improvement of Living and Working Conditions; 1993.

13. Tetley J, Hanson E, Clarke A. Older people, telematics and care. In: Warnes AM, Warren L, Nolan $\mathrm{M}$, editors. Care services for later life: Transformations and critiques. London: Jessica Kingsley Publications; 2001. p. 243-58.

14. Wylde M, Valins MS. The impact of technology. In: Valins MS, Salter D, editors. Futurecare: New directions in planning health and care environments. Oxford: Blackwell Science; 1996. p. 5-24.

15. Stip E, Rialle V. Environmental Cognitive Remediation in Schizophrenia: Ethical Implications of "Smart Home" Technology. Can J Psychiatry 2005;50(5):281-91.

16. Bonner S. Assisted Interactive Dwelling House. Proceedings of the 4th TIDE Congress, Helsinki, Finland 1998.

17. Junestrand S, Keijer U, Molin G, Tollmar K. User Study of Video Mediated Communication in the Domestic Environment with Intellectually Disabled Persons. Int J Hum Comput Interact 2003;15(1):87-103

18. Helal A, Mann W, Elzabadani H, King J, Kaddoura Y, Jansen E. Gator Tech Smart House: A Programmable Pervasive Space. IEEE Computer Magazine 2005;64-74.

19. Adlam T, Gibbs C, Orpwood R. The Gloucester Smart House bath monitor for people with dementia. Phys Med 2001;17(3):189.

20. Demongeot J, Virone G, Duchêne F, Benchetrit G, Hervé T, Noury N, et al. Multi-sensors acquisition, data fusion, knowledge mining and alarm triggering in health smart homes for elderly people. C R Biol 2002;325(6):673-82.
21. Cook DJ, Youngblood M, Heierman EO, Gopalratnam K, Rao S, Litvin A, et al. MavHome: an agent-based smart home. Proceedings of the First IEEE International Conference on Pervasive Computing and Communications (PerCom) 2003;521- 4

22. Creating an Autonomy-Risk Equilibrium (CARE) http://www.elite-care.com/oatfield-tech.html. Last accessed April 2006

23. Intille SS, Larson K, Munguia Tapia E, Beaudin J, Kaushik P, et al. Using a live-in laboratory for ubiquitous computing research. In: Fishkin KP, Schiele B, Nixon P, Quigley A, editors. Proceedings of PERVASIVE 2006, vol. LNCS 3968. Berlin, Heidelberg: Springer-Verlag; 2006. p. 349-65.

24. Woolham J, Frisby B. How techology can help people feel safe at home. Journal of Dementia Care 2002;10(2):27-9.

25. Rialle V, Rumeau P, Ollivet C, Herve C. Smart Homes. In: Wootton R, Dimmick SL, Kvedar JC, editors. Home Telehealth: Connecting Care Within the Community RSM Press; 2006.

26. The Duke Smart Home Project. http://www. smarthome.duke.edu/ Last Accessed April 2007.

27. Elger G, Furugren B. SmartBo-an ICT and computer based demonstration home for disabled people. In Proceedings 3rd TIDE Congress: Technology for Inclusive Design and Equality Improving the Quality of Life for the European Citizen, Helskinki, Finland; 1998.

28. The National Knowledge Centre for Home Automation and Smart Living. Smartest Home. http://www.smart-homes.nl/engels/woning/ index.html Last accessed, April 2007.

29. Demiris G, Skubic M, Keller J, Rantz MJ, Parker Oliver D, Aud MA, et al. Nurse Participation in the Design of User Interfaces for a Smart Home System. In: Proceedings of the International Conference on Smart Homes and Health Telematics, Belfast, N. Ireland, June; 2006. p. 66-73.

30. Sandström G, Gustavsson S, Lundberg S, Keijer U, Junestrand S. Long-term Viability of Home Network Systems - Business Modelling and Conceptual Requirements on Technology. In: Slona A. Proceedings of the Home-Oriented Informatics and Telematics(HOIT) 2005 IFIP Conference. New York: Springer; 2005. p. 71-86.

31. Kawarada A, Nambu, M, Tamura T, Ishijima M, Yamakoshi K, Togawa T. Fully automated monitoring system of health status in daily life. Proceedings of the 22nd Annual International Conference of the IEEE Engineering in Medicine and $\mathrm{Bi}$ ology Society 2000;1:23-8.

\section{Correspondence to:}

George Demiris, PhD

University of Washington

BNHS-Box 357266

Seattle, WA 98195-7266

USA

Tel: (206) 221-3866

Fax: (206) 543-4771

E-mail: gdemiris@u.washington.edu 